\title{
Relationship between anxiety and insomnia in clinical clerkship students during COVID-19 pandemic
}

\author{
Maria Sekartaji, * Muhammad Irsan, Resty Puspita Sari, Muhammad Adnan, Labitta Pachira Aquaira, \\ Shabrina Rifka Farahiya, Firdaus Hafidz
}

Department of Nutrition, Faculty of Medicine, Public Health, and Nursing, Universitas Gadjah Mada, Yogyakarta, Indonesia

\section{KEYWORDS}

Anxiety

Insomnia

Clinical clerkship

student

COVID-19
ABSTRACT During the COVID-19 pandemic, there has been an increase in anxiety disorders among the general population, including those clinical clerkship students who are associated with health care services. There has been limited studies conducted regarding this important topic, especially during the COVID-19 pandemic. This study aimed to know the prevalence of anxiety and insomnia, as well as the correlation between them, in clinical clerkship students during the COVID-19 pandemic. An online survey was conducted using a cross-sectional approach with 229 clinical clerkship students from batch 2015 at the Faculty of Medicine, Public Health and Nursing Universitas Gadjah Mada. This study used the Insomnia Severity Index (ISI) and General Anxiety Disorder-7 (GAD-7), administered using Google Forms. Data were analyzed using chi-squared tests. We collected 101 responses. There were $41.6 \%$ male respondents and $58.4 \%$ female respondents with ages ranging from 21 to 26 . The results show $26.7 \%(95 \% \mathrm{Cl}: 8.1$ $35.4 \%$ ) of students experienced anxiety and $44.6 \%$ (95\% CI: $34.9-54.3 \%$ ) of students experienced insomnia throughout the COVID-19 pandemic. There is a correlation between anxiety and insomnia among clinical clerkship students during the COVID-19 pandemic. Clinical clerkship students with an anxiety disorder have 2.62 times greater risk of experiencing insomnia $(p<$ 0.001 ). The correlation between insomnia and anxiety during COVID-19 pandemic is vital because clinical clerkship students are directly involved in health care services and they could risk the safety of patients. Thus, it is important to conduct the proper course of actions to reduce the risk of mental health problems during pandemic conditions. Also, further research is needed to have a better understanding of the impact of the pandemic reactions on learning performance.

(C) The Journal 2021. This article is distributed under a Creative Commons Attribution-ShareAlike 4.0 International license.

\section{Introduction}

The Coronavirus Disease 2019 (COVID-19) is a worldwide crisis which first emerged from Wuhan, Hubei Province, China. ${ }^{1}$ The number of cases in Indonesia had reached 174,796 by the end of August 2020 since the first case was announced on March $18^{\text {th }}, 2020 .^{2}$ This condition affects many sectors in Indonesia including social, economy, education, tourism, and health, which endured massive impact because of the lack of preparedness within the health system. ${ }^{3}$ This event also happens to have a huge impact on the majority of human population and has produced unprecedented changes in our life..$^{1,3}$

Anxiety is a feeling of excessive worry which can

*Correspondence: maria.sekartaji@mail.ugm.ac.id Department of Nutrition and Health, Faculty of Medicine, Public Health and Nursing, Universitas Gadjah Mada, Jl. Farmako, Sekip Utara, Yogyakarta 55281, Indonesia be characterized by restlessness, fatigue, difficulty in concentrating, irritability, tension, and sleep disturbances. This disorder usually occurs when someone is facing something new or is in the search for self-identity. ${ }^{1,4}$ The COVID-19 outbreak has led to higher anxiety levels in the general population. Several factors associated with such conditions are the virus infection itself, having infected family members, and close contact with identified patients. Other factors regarding the psychosocial condition include working as a healthcare professional and lack of emotional support which also increase a person's anxiety level. ${ }^{5}$

The occurrence of anxiety has been associated with insomnia in several studies. ${ }^{6,7,8}$ Both are problems which are often found in college students and young adults in general. Insomnia is a sleep disorder that can be characterized by difficulty starting or maintaining sleep or waking up too early and unable to return 
to sleep. It can cause significant disruption in social, educational, academic, behavioral, or other aspects of life. ${ }^{1,4}$

Medical students, both in undergraduate and clinical clerkship programs, are reported having an increased anxiety due to COVID-19 pandemic. $^{9}$ A study revealed that anxiety levels in medical students associated with healthcare services were significantly higher than the medical staff and community population. It was possibly because they lack experience in controlling infectious disease in high-risk environments, the fear of medical errors, physical and emotional exhaustion due to a highpressure health care system, rapid changes in medical information and procedures, self-perception of risk to themselves, the impact of pandemic on lifestyle, fear of inadequate medical equipment such as masks and gloves, long working hours, and separation from families. ${ }^{10}$ However, since before the COVID-19 pandemic, medical students already have high rates of mental health problems and they are less likely to seek support. ${ }^{9}$ Those who are in clinical clerkship program, especially, have a higher rate of anxiety due to more responsibilities in patient safety. ${ }^{11}$ Therefore, it is important to raise public awareness on this critical topic.

To the best of our knowledge, there has been limited studies conducted regarding this important topic, particularly during the COVID-19 pandemic. Studies identified while conducting this research, were mostly describing or reporting increased mental health burdens among the general public during the pandemic; or anxiety, insomnia, and depression among medical students before the pandemic. Considering the serious effects of anxiety and insomnia on clinical clerkship students' professional and academic life, we conducted this study to know the prevalence of anxiety and insomnia, as well as the correlation between them, in clinical clerkship students during the COVID-19 pandemic.

\section{Methods}

We used data from a cross-sectional study among 229 clinical clerkship students of batch 2015 at the Faculty of Medicine, Public Health and Nursing, Universitas Gadjah Mada. The questionnaire was distributed via
Google Forms in social media platforms including Line, WhatsApp, and Instagram, which could be accessed within the time period of August $28^{\text {th }}$ to August $30^{\text {th }}, 2020$. This study used a questionnaire that could be accessed via the following link: http:// bit.ly/DampakCovidKoasUGM. The questionnaire consisted of demographics such as initials, gender, age, clinical rotation group, location, and whether the respondents were undergoing any anxiety or depression treatment. Other sections consisted of questions using standardized measurements of insomnia and anxiety, with the Insomnia Severity Index (ISI) and General Anxiety Disorder-7 (GAD-7) surveys. The researchers had consulted regarding the constructs of the study with the experts for their professional judgment and input to increase the validity and reliability of these methods.

The independent variable in this study was anxiety found in medical students of batch 2015 affected by the COVID-19 pandemic. Whereas, the dependent variable in this study refers to the insomnia triggered or worsened by the anxiety. The researchers used the Insomnia ISI and GAD-7 to measure both of these variables. The ISI score was interpreted as absence of insomnia (0-7), subthreshold insomnia (8-14), moderate insomnia (15-21), and severe insomnia (22-28); with excellent reliability and validity among university student ${ }^{12}$. GAD-7 score was categorized into minimal (0-4), mild (5-9), moderate (10-14), and severe (15-21). A score of $\geq 10$ held a possibility of clinically diagnosed GAD, and is reliable and valid to use among university students ${ }^{13}$. Referring to the score, in this study we simplified our finding into 'No Insomnia' and 'Insomnia' with cutoff point of 8 in ISI, and 'No Anxiety' and 'Anxiety' with cutoff point of 10. We described the relationship between anxiety and insomnia in clinical clerkship students during the COVID-19 pandemic using a chi-squared test $\left(x^{2}\right)$. Significant value was set as $p<0.05$.

\section{Result}

From 229 students we approached, 106 agreed to respond but 5 failed to complete all the forms required. Therefore, a total of 101 clinical clerkship students of batch 2015 were included in this study. There were $42(41.6 \%)$ male respondents and 59 (58.4\%) of female respondents with ages ranging from 21 to 26 . There was no significant difference in 
Table 1. The prevalence of anxiety and insomnia by gender

\begin{tabular}{lllllll}
\hline Gender & Anxiety & No anxiety & $\boldsymbol{p}$-value & Insomnia & No insomnia & $p$-value \\
\hline Male (42) & $8(29.6 \%)$ & $34(45.9 \%)$ & & $16(35.6 \%)$ & $26(46.4 \%)$ & \\
Female (59) & $19(70.4 \%)$ & $40(54.1 \%)$ & 0.213 & $29(64.4 \%)$ & $30(53.6 \%)$ & 0.369 \\
Total & $27(26.7 \%)$ & $74(73.3 \%)$ & & $45(44.6 \%)$ & $56(55.4 \%)$ & \\
\hline
\end{tabular}

Table 2. General Anxiety Disorder-7 (GAD-7) score distribution ( $N=101$ )

\begin{tabular}{lll}
\hline Anxiety Level & Frequency & Percent \\
\hline Minimal/No anxiety & 47 & 46.5 \\
Mild Anxiety & 27 & 26.7 \\
Moderate Anxiety & 18 & 17.8 \\
Severe anxiety & 9 & 8.9 \\
\hline GAD Score: Minimal/No Anxiety= 0-4, Mild Anxiety $=5-9$, Moderate Anxiety = 10-14, Severe Anxiety $=15-21$
\end{tabular}

Table 3. Insomnia severity index score distribution ( $N=101)$

\begin{tabular}{lll}
\hline Level & Frequency & Percent \\
\hline No Insomnia & 57 & 56.4 \\
Subthreshold Insomnia & 33 & 32.7 \\
Clinical Insomnia (Moderate) & 10 & 9.9 \\
Clinical Insomnia (Severe) & 1 & 0.9
\end{tabular}

ISI Score: No Insomnia= 0-7, Subthreshold Insomnia= 8-14, Moderate Insomnia = 15-21, Severe Insomnia = 15-21

Table 4. The association between anxiety and insomnia

\begin{tabular}{lllll}
\hline Group & Insomnia & No Insomnia & PR* $(95 \% \mathrm{Cl})$ & $\boldsymbol{p}$-value \\
\hline Anxiety & $22(81.5 \%)$ & $5(18.5 \%)$ & \multirow{2}{*}{$2.62(1.79-3.85)$} & $<0.001$ \\
No anxiety & $23(31.1 \%)$ & $51(68.9 \%)$ & & \\
\hline
\end{tabular}

*Prevalence ratio; $\mathrm{Cl}$, confidence interval

the prevalence of anxiety and insomnia by gender (Table 1). In the time of sampling, among the 101 samples, 47 were enrolled in 10 weeks term of 'major' department (Internal Medicine, Surgery, Obstetrics/Gynecology, and Pediatrics), 50 in 4 weeks of 'minor' department (Forensic, Dermato/ Venereology, Anaesthetic, Psychiatry, Public Health, Neurology, Ophtalmology; Ear, Nose \& Throat), and 4 having off week.

The prevalence of anxiety and insomnia among the students was $26.7 \%$ and $44.6 \%$, respectively. The mean GAD-7 score was $6.24 \pm 5.26$ (maximum $=20$ ), with the spread of score categorization explained in Table 2.

On the other hand, the mean ISI score was 7.69 \pm 6.09 (maximum $=25$ ), with the spread of score categorization explained in Table 3.

Table 4 shows that there was a correlation between anxiety and insomnia on clinical clerkship students during the COVID-19 pandemic. Of 28 students with anxiety, 22 (79.3\%) had insomnia and only $5(20.7 \%)$ had no insomnia. Thus, clinical clerkship students with anxiety have a 2.62 times greater risk of experiencing insomnia (Prevalence risk 2.62 (1.79-3.85), $p=.000)$.

\section{Discussion}

Our study found that $26.7 \%$ of clinical clerkship students suffered from anxiety and $44.6 \%$ of clinical clerkship students experienced insomnia, and of those who suffered anxiety, they were 2.62 times more likely to have insomnia. This number of $26.7 \%$ of respondents having anxiety is lower than the Asian prevalence of $35.2 \%$, but concordant with the global prevalence of $27.5 \%{ }^{14}$ Anxiety itself is a topic that has been less discussed among medical students, than the more popular study topics such as depression. Even anxiety can be debilitating, 
and since it has been less recognized and studied, it can go undetected and untreated. ${ }^{14}$ Insomnia is another important parameter to explore, because it is associated with quality of life in many studies. ${ }^{15,16}$ Research found that it is one of the most common sleep disorders, with prevalence between $10 \%$ and $40 \%$ across studies. ${ }^{17,18}$ Prevalence of sleep disorders among young adults is increasing globally and in adolescents aged 13-16, prevalence of insomnia was reported to be as much as $11 \%{ }^{19}$

Students with insomnia experience more problems with physical and psychological health. Improving sleep quality has been shown to decrease the incidence of chronic diseases such as major depressive disorders, psychosis, addictions, cardiovascular, metabolic and inflammatory disease risks. ${ }^{20}$ One of the most robust associations between sleep disruption and emotional functioning involves how the role of anxiety and insomnia increases the likelihood of developing a mood or anxiety disorder. ${ }^{21-23}$

Anxiety is a 'normal' emotion that is experienced by everyone, as a response to some general stress or threat. It could be seen as a state of alarm and activation of fight-and-flight response to danger, real or perceived, both physiologically or psychologically. Anxiety is also a trait that is attached as a person's character feature, likely reflecting a long time maladaptive response to stress; as varying genetic background, developmental and early life experiences, shape a person's perception of experiencing stress. There is no hard distinction of what 'abnormal' anxiety is as a state of mind, but pathological anxiety differs in the sense of fear that is irrational, as a response to a threat that is not always really present or actively threatening to guarantee an immediate danger. $(24,25)$

Whether the anxiety is rational or not, state or trait, features of anxiety appear as signs of alertness and arousal, which could lead into changes of sleepwake patterns. Sleep arousal is essential to maintain a nervous system state that favors survival during a stressful event. As a response to stress, it has been described by having hormonal, behavioral, and autonomic components. While still working in a close relationship, different components of the stress system respond to different kinds of stress. For example, a physiological stressor like hypoxia will be responded to by an autonomic-nervous (AN) system, which differs from the response to a complex environmental danger like emotional stress that involves the corticotrophin releasing hormone (CRH) system. (25)

Both acute and chronic stress have prominent effects on sleep which are regulated by the hypothalamic-pituitary-adrenal (HPA) axis and generally the sympathetic nervous system. Exposure to stress is known to disrupt the sleep structure and sleep-wake regulation, as patients with insomniac complaint show increased activity of HPA activity and sympathetic tone increase. The nature of both the HPA and AN systems will stimulate each other. This feed-forward mechanism is susceptible to dysfunction, because it can retain an arousal state despite being out of the stressful situation. It is proposed that this dysfunctional state can lead to anxiety and depressive disorders, creating a loop of disruption. (25) To answer the question about which one is more likely to come before the other?: Reports shows that anxiety occurs before insomnia in as many as $43.5 \%$ of chronic insomniac cases, while in $38.6 \%$, it happens in parallel; and in $18 \%$ cases, insomnia appears before anxiety. In clinical cases, it is concluded that anxiety problems as a part of psychiatric history, are correlated to the severity and chronicity of insomnia experienced. (26)

In terms of public health, insomnia co-morbid with anxiety gives rise to more complications and greater burdens than does each disorder alone and treating anxiety improves co-morbid insomnia symptoms. ${ }^{23,-27,28}$ While treating clinical insomnia and anxiety is not without medication, there are efforts that students can attempt to prevent and deal with them. Simple self-administered behavioral changes like maintaining a good sleep hygiene, making a sleep journal and peer-counselling can be done if seeking formal therapy is not available yet. ${ }^{28}$ Maintaining anxiety levels by doing hobbies, routine exercise, and regulating a healthy diet are also recommended. During the pandemic situation, it is even advised to retreat from too much media and news especially regarding COVID-19, if they disturb you in some way. 29 
According to the data we have gathered, this is the first study conducted to observe the correlation between anxiety and insomnia that happens within the clinical clerkship student population during COVID-19 pandemic. The pandemic situation has hit everyone in the general population. It affects not only personal and public health, but also social relationships, education, and importantly economic conditions. Emergency guidelines to reduce the impact of the pandemic as a wide-scale disaster, that are endorsed by the government, include restrictions of gatherings and closing of educational institutions, and have created great changes in all people's life. ${ }^{29}$ These measures add additional stress to the people's own fear for their health, mazy social media, lack of physical and mental health knowledge, and lack of physiological coping methods, which can negatively impact the public mental health greatly. ${ }^{29-30}$

Medical students in the clerkship program especially have another academic challenge during the pandemic. Clerkship programs that were designed to involve bed-side teachings, emergency setting, and hands-on training have been greatly shifted into online learning, which cannot replace real-time, realpatient interactions to practice what they learned in pre-clinical settings. ${ }^{31}$ This pandemic is undoubtedly an unexpected problem that none of the clerkship students were prepared for appropriately. As they train and prepare for their board examination to qualify as a competent doctor, thiese changes of study methods affect their practical preparedness to be a medical doctor, in this time of high demand for competent medical workers.

How to prepare these medical students to reach their competency, is another concern needing to be considered by the academic institutions, lecturers, and medical students. In the traditional curriculum, proficiency is measured mostly by records or logs of case findings, skills, and real patient clinical examinations. All of them require the normal circumstances when students are able to be sent to a type $\mathrm{C}$ or $\mathrm{B}$ hospital in a more peripheral region, where they can take part in ward care or an emergency setting. A standardized online curriculum had to be established, including the hours needed, mechanism of either synchronized and asynchronized methods, and enough practical learning. Hands-on training is essential for competency, and the clerkship course cannot be abandoned. Students can be divided into smaller groups and shorter shifts for their bedside learning. By mixing these experiences with online alternatives for meetings, we should be able to maintain the precaution measures. We also need to consider the possibility of expanding the number of training hospitals within the less COVID-19 hit area. Extensive considerations still need to be taken. Many questions arise such as: Do these hospitals have enough patients, or supervisors; do they have clear protocols to protect the students; et cetera.

As discussed before, the board exam to ensure medical doctors' competency is one of the academic aspects that influence the stress level of the students. In our country, this exam has been delayed once and modified into a written exam only, without the clinical exam. ${ }^{32}$ For the earlier batch of students, this mean a delay in graduation, and also changes in practice. We need to prepare also for the next period of exam, since it will be taken mostly by the students that have been impacted by the pandemic longer at least for several more months. This brings up the valid question: Is the same exam method able to be applied to these students whose clerkship program was spent mostly online? We need to consider alternative methods like using a from-home but still real-time exam, using levelled short cases, essays, and options that are able to measure clinical skills that should have been honed during the clerkship.

To compare with other countries, final year medical students, across Europe and United States, have been recruited to become the frontliners of health care by 'bypassing' board exam, either to have an accelerated exam and being dispatch right into the national health system under a provisional licensure. This approach is also done with graduating residents in Canada, giving them opportunities to work within their competence before taking the earliest exam possible. ${ }^{33}$ While maintaining the supply of doctors, the utmost important safeguard to do is then to protect them with proper personal protective equipment (PPE). If these kinds of policies are to be done in Indonesia, there are several conditions that need to be considered. The first is because these 'new personnel' are somehow still medical students and not registered doctors yet under the law, their 
status at the hospital is questionable. The questions arise: Are the faculty responsible to supply their PPE, or are they under the ministry support like internship doctors, or under the hospital own expenses? And the next question is, are they actually competent enough to work independently?

Our study has some limitations. First, we used a self-reporting survey rather than using face to face interviews that can gather more information than questionnaires as a standalone. This survey was conducted online and in a narrow time range, which can possibly hinder the data because of the limited Internet access, and disability to reach a wider range of respondents. Hence, we were also only able to have minimal measurements in a relatively small population, so the results may not reflect the general population well. As a cross-sectional study, we can only estimate and correlate anxiety and insomnia as episodes, and were not able to do longitudinal and indepth observations. Thus, the interpretation of this study is very limited, and a larger and retrospective or prospective study in the future is required to verify the results.

\section{Conclusion}

Many medical students are having anxiety during their clinical clerkship in the pandemic situation, which correlates with their insomniac sleep pattern. Our opinion is that the pandemic situation not only affects anxiety prone medical student as normal citizens, but also from the academic perspective. Measures have to be taken especially by academic institutions and educators to consistently construct a safe-guarding and empowering environment for medical students in their clerkship program during the pandemic situation, in order to reach the goals of the clerkship itself while still maintaining safety protocols. Such actions are vital because clinical clerkship students -albeit limited, are directly involved in health care services and any human error could risk the safety of the patients.

\section{Acknowledgements}

The authors would like to express gratitude to all respondents who were involved in this study and the Dean of the Faculty of Medicine, Public Health and Nursing, UGM. This work was supported by the
Public Health Sciences Program, and approved by the Medical and Health Research Ethics Committee of the Faculty of Medicine, Public Health and Nursing, UGM.

\section{Conflict of interests}

The authors stated that all of them have no conflict of interests in this paper.

\section{References}

1. Morin CM, Carrier J. The acute effects of the COVID-19 pandemic on insomnia and psychological symptoms. Sleep Medicine. 2020; S1389-9457(20): 30261-6.

2. Gugus Tugas Percepatan Penanganan COVID-19. Infografis COVID-19 [Internet]. Jakarta: Gugus Tugas Percepatan Penanganan COVID-19; 2020 [updated 2020 August 31; cited 2020 September 3]. Available from: https://covid19.go.id/p/ berita/infografis-covid-19-31-agustus 2020

3. Djalante R, Lassa J, Setamarga $D$, Sudjatma $A$, Indrawan $\mathrm{M}$, Haryanto $\mathrm{B}$, et al. Review and analysis of current responses to COVID-19 in Indonesia: period of January to March 2020. Prog Disaster Sci. 2020;(6):100091

4. American Psychiatric Association. Diagnostic and Statistical Manual of Mental Disorders. 5th. Arlington: American Psychiatric Publishing, 2013. Section II: Diagnostic Criteria and Codes; p.189422.

5. Chou Y, Agus D, Juliawati DJ. Perbedaan proporsi gangguan depresi dan gangguan cemas antara mahasiswa preklinik dan klinik. The Indonesian Journal of Medical Education. 2017; 6(3): 146152.

6. Zhao $H$, He $X$, Fan $G$, et al. COVID-19 infection outbreak increases anxiety level of general public in China: involved mechanisms and influencing factors. J Affect Disord. 2020;276:446-52.

7. Forbes EE, Bertocci MA, Gregory AM, et al. Objective sleep in pediatric anxiety disorders and major depressive disorder. J Am Acad Child Adolesc Psychiatry. 2008; 47(2): 148-155.

8. Silva VM, Magalhaes JEdM, Duarte LL. Quality of sleep and anxiety are related to circadian preference in university students. PLOS ONE. 
2020; 15(9): e0238514.

9. Choueiry N, Salamoun T, Jabbour H, El Osta N, Hajj A, Khabbaz LR. Insomnia and relationship with anxiety in university students: a crosssectional designed study. PLoS ONE. 2016; 11(2): e0149643.

10. Chandratre S. Medical students and COVID-19: challenges and supportive strategies. J Med Educ Curric Dev. 2020; (7): 1-2.

11. Vahedian-Azimi A, Moayed MS, Rahimibashar F, Shojaei S, Ashtari S, Pourhoseingholi MA. Comparison of the severity of psychological distress among four groups of an Iranian population regarding COVID-19 pandemic. BMC Psychiatry. 2020; 20(402): 1-7.

12. Veqar Z, Hussain ME. Validity and reliability of insomnia severity index and its correlation with Pittsburgh sleep quality index in poor sleepers among Indian university students. Int J Adolesc Med Health. 2017 Jan 7;32(1):/j/ijamh.2020.32. issue-1/ijamh-2016-0090/ijamh-2016-0090.xml.

13. Alghadir, A., Manzar, M. D., Anwer, S., Albougami, A., \& Salahuddin, M. Psychometric properties of the generalized anxiety disorder scale among Saudi university male students. Neuropsychiatric disease and treatment. 2020;16:1427-1432.

14. Johnson EO, Roth T, Schultz L, Breslau N. Epidemiology of DSM-IV insomnia in adolescence: lifetime prevalence, chronicity, and an emergent gender difference. Pediatrics. 2006;117(2): e247-56.

15. Quek TT, Tam WW, Tran BX, Zhang M, Zhang Z, Ho CS, et al. The global prevalence of anxiety among medical students: a meta-analysis. Int J Environ Res Public Health. 2019;16(15): 2735.

16. Leistner SM, Klotsche J, Dimopoulou C, Athanasoulia AP, Roemmler-Zehrer J, Pieper $L$, et al. Reduced sleep quality and depression associate with decreased quality of life in patients with pituitary adenomas. Eur J Endocrinol. 2015; 172(6): 733-43.

17. Chou Y, Agus D, Juliawati DJ. Perbedaan Proporsi Gangguan Depresi dan Gangguan Cemas antara Mahasiswa Preklinik dan Klinik. The Indonesian Journal of Medical Education. 2017; 6(3): 146152.

18. Blais FC, Morin CM, Boisclair A, Grenier V, Guay B.
Insomnia: prevalence and treatment of patients in general practice. Can Fam Physician. 2001; (47):759-67.

19. Leger D, Partinen $M$, Hirshkowitz M, Chokroverty $\mathrm{S}$, Hedner J. Characteristics of insomnia in a primarycare setting: EQUINOX survey of 5293 insomniacs from 10 countries. Sleep Med. 2010; 11(10): 987-98.

20. Sekercioglu N, Curtis B, Murphy S, Barrett B. Sleep quality and its correlates in patients with chronic kidney disease: a cross-sectional design. Ren Fail. 2015; 37(5): 757-62.

21. Carroll JE, Seeman TE, Olmstead R, Melendez G, Sadakane R, Bootzin R, et al. Improved sleep quality in older adults with insomnia reduces biomarkers of disease risk: pilot results from a randomized controlled comparative efficacy trial. Psychoneuroendocrinology. 2015; (55):184-92.

22. Alfano CA, Pina AA, Zerr AA, Villalta IK. Presleep arousal and sleep problems of anxietydisordered youth. Child Psychiatry Hum Dev. 2010; 41(2):156-67.

23. Gregory AM, O'Connor TG. Sleep problems in childhood: a longitudinal study of developmental change and association with behavioral problems. J Am Acad Child Adolesc Psychiatry. 2002; 41(8): 964-71.

24. Chand SP, Marwaha R. Anxiety. [Updated 2020 Nov 29]. In: StatPearls [Internet]. Treasure Island (FL): StatPearls Publishing; 2020 Jan-. Available from: https://www.ncbi.nlm.nih.gov/books/ NBK470361/

25. Staner L. Sleep and anxiety disorders. Dialogues Clin Neurosci. 2003;5(3):249-58.

26. Ohayon MM, Roth T. Place of chronic insomnia in the course of depressive and anxiety disorders. J Psychiatr Res. 2003;37(1):9-15.

27. Mason EC, Harvey AG. Insomnia before and after treatment for anxiety and depression. J Affect Disord. 2014; 168:415-21.

28. Belleville G, Cousineau H, Levrier K, St-PierreDelorme ME. Meta-analytic review of the impact of cognitive-behavior therapy for insomnia on concomitant anxiety. Clin Psychol Rev. 2011; 31(4):638-52.

29. Islam MS, Ferdous MZ, Potenza MN. Panic 
and generalized anxiety during the COVID-19 pandemic among Bangladeshi people: an online pilot survey early in the outbreak. J Affect Disord. 2020; (276): 30-37.

30. Salari N, Hosseinian-Far A, Jalali R, Vaisi-Raygani A, Rasoulpoor S, Mohammadi M, et al. Prevalence of stress, anxiety, depression among the general population during the COVID-19 pandemic: a systematic review and meta-analysis. Global Health. 2020; 16(1): 57.

31. Kelly, Hwei LRY, Octavius GS. Coronavirus outbreaks including COVID-19 and impacts on medical education: a systematic review. $J$ Community Empowerment Health. 2020;3(2):130-140.
32. Panitia Nasional Uji Kompetensi Mahasiswa Program Profesi Dokter. Pembatalan Ujian UKMPPD periode Mei 2020 [Internet]. Jakarta: Panitia Nasional Uji Kompetensi Mahasiswa Program Profesi Dokter; 2020 [updated 2020 March 26; cited 2020 September 6]. Available from: https://pnukmppd.kemdikbud.go.id/ index.php/berita/1793-Pembatalan-UjianUKMPPD-periode-Mei-2020

33. Fong ZV, Qadan M, McKinney R Jr, Griggs CL, Shah PC, Buyske J, Sachdeva AK, Callery MP, Altieri MS. Practical implications of novel coronavirus COVID-19 on hospital operations, board certification, and medical education in surgery in the USA. J Gastrointest Surg. 2020;24(6):1232-36 